\title{
Organic Compounds as Geochemical Tracers in Planetary Exploration
}

\author{
KIRTLAND J. ROBINSON ${ }^{1}$, CHRISTIANA BOCKISCH ${ }^{2}$, IAN \\ R. GOULD ${ }^{2}$, KRISTOPHER M. FECTEAU ${ }^{2}$, JEFFREY S. \\ SEEWALD ${ }^{1}$, EVERETT L. SHOCK ${ }^{2}$ \\ ${ }^{1}$ Woods Hole Oceanographic Institution, Woods Hole, MA \\ krobinson@whoi.edu \\ ${ }^{2}$ Arizona State University, Tempe, AZ
}

Environmental abundances of organic compounds can be used to determine the conditions of geochemical systems that are difficult or even impossible to sample directly, including subsurface systems or settings from the distant past. A variety of reduction/oxidation (redox) reactions equilibrate and therefore reflect temperatures and redox states in hydrothermal systems [1-5]. However, organic redox reactions are typically sluggish relative to other types of reactions, which limits their use as geochemical tracers in lower temperature systems. More rapid reactions among organic compounds can be used to constrain $\mathrm{pH}$, which may lower the temperatures for organic geochemical indicators. In the present study, we examine a type of reaction called substitution, which typically proceeds more rapidly than redox reactions. We focus on organic nitrogen reactions because the ionizable nature of nitrogen species (e.g., amines) causes total (neutral + ionized) product and reactant abundances to shift as a function of $\mathrm{pH}$, thereby providing a tool to constrain $\mathrm{pH}$. Hydrothermal experiments were performed from $200^{\circ} \mathrm{C}$ to $300^{\circ} \mathrm{C}$ at liquid-vapor water saturation pressures while controlling $\mathrm{pH}$ to characterize a variety of substitution reactions involving oxygen- and nitrogen-bearing organic compounds. Multiple reactions involving alcohols and amines were observed to simultaneously equilibrate in under 72 hours at $250^{\circ} \mathrm{C}$, resulting in steady-state abundances that reflected reaction conditions. Furthermore, the mechanisms and kinetics for certain reactions were determined as a function of temperature and used in combination with estimated thermodynamic reaction properties to model equilibration timescales across a range of reaction conditions. The results demonstrate that certain organic nitrogen reactions could serve as temperature and $\mathrm{pH}$ probes across aqueous environments with diverse thermal histories.

[1] Shock, E. (1988) Geol., 16, 886-890

[2] Helgeson, H. et al. (1993) GCA, 57, 3295-3339

[3] Seewald, J. (1994) Nature, 370, 285-287

[4] Cruse, A. \& Seewald, J. (2006) GCA, 70, 2073-2092

[5] Seewald, J. et al. (2006) GCA, 70, 446-460 